\title{
Effects of CuO Nanoparticles on the Growth of Kale
}

\author{
Javier Vassell ${ }^{1}$, Alexis Racelis ${ }^{2}$ and Yuanbing Mao ${ }^{1,2, *}$
}

With the growing population and degrading environment, a new field of study is looking into the use of nanoparticles to enhance the quality and growth of crops, and to compensate for the sterilized soils. The present study was conducted to examine the effects of copper oxide nanoparticles (CuO NPs) on kale (Brassica oleracea) plant growth after treating its seeds with aqueous solutions with three concentrations of $\mathrm{CuO}$ NPs for 24 hours. The treated seeds were directly sown and the kale plants were harvested after 34 days. The results showed that the length of the roots and the shoots of the obtained kale were positively affected by the CuO NPs: larger increase came from the seeds treated with 70 ppm $\mathrm{CuO}$ NPs while both treated seeds by $\mathrm{CuO}$ NPs showed increased growth compared with the control sample. Moreover, the dry weight of the kale plants was also impacted by the treatment with $\mathrm{CuO}$ NPs: larger increase was produced from the seeds treated with 70 ppm $\mathrm{CuO}$ NPs relative to the control. This study shows that the application of $\mathrm{CuO}$ NPs at appropriate concentrations causes proliferation on the growth and development of kale.

Keywords: Nanoparticles; Copper oxide; Kale; Seed; Growth

Received 2 December 2018, Accepted 12 March 2019

DOI: $10.30919 /$ esmm $5 f 212$

\section{Introduction}

By 2050, the projected global population is estimated to be 9 billion. With the projected increase in population, there will have to be great changes in the agricultural world. To supply the world with healthy nutrition, the production of agriculture and food will have to increase by about $60 \%$ to accommodate for the increased demand. 'With conventional farming practices, nutrients are striped from the soil and supplemented with chemical fertilizers that are harmful to the environment. This method is not only expensive but also unsustainable. Nanotechnology has been a rapidly growing field of studies in the recent decades. Nanoparticles are particles smaller than 100 nanometers (nm). Because of their extremely small size, they have very large surface area relative to size. ${ }^{2}$ This big difference in surface area relative to size causes nanoparticles to react and exude properties that are not characteristic of the same material when it is not nano-sized.

There are many personal and commercial applications of nanoparticles in various fields, such as tires, drug carriers, semiconductors, sporting goods, and cosmetics. ${ }^{3}$ The number of industries that are using nanoparticles are increasing rapidly. For example, they are currently being used in biotechnology and biomedicine industries. ${ }^{4}$ While there are many different types of nanoparticles, metal oxide nanoparticles have been most widely used. For instance, they have been widely applied in gene therapy, ${ }^{5}$ textiles, ${ }^{6}$

${ }^{1}$ Department of Chemistry, University of Texas Rio Grande Valley, 1201 West University Drive, Edinburg, Texas 78539, USA

${ }^{2}$ School of Earth, Environmental, and Marine Sciences, University of Texas Rio Grande Valley, 1201 West University Drive, Edinburg, Texas 78539, USA

*E-mail: yuanbing.mao@utrgv.edu sunscreen and cosmetics, electro disinfectants, ${ }^{8}$ and many other fields. Thus, it is inevitable that these nanoparticles will flow into the environment and interact with the ecosystem. ${ }^{8}$ As one example, zinc oxide is one example that is used in the commercial industry such as in creams and cosmetics but it has also shown the ability to help plants grow. $^{9}$

A new field of study is looking into the use of nanoparticles to enhance the quality and growth of crops, and to compensate for the sterilized soils. The three main elements utilized by plants are Nitrogen $(\mathrm{N})$, Phosphate $(\mathrm{P})$ and Potassium $(\mathrm{K})$ and are noted as NPK. However, there are many micronutrients that affect the absorption of the macronutrients and the overall growth of the plant. Some studies investigate the effect of the nanoparticles on the soil which then results in an absorption rate in each different plant. Nanotechnology has also impacted the world of agriculture in the micronutrient scales. Some papers have discussed the issues of increasing the growth of the plants using nanotechnology. ${ }^{10-13}$ Other factors that have a big part to play in the viability of plants are the germination. Research has showed that nanoparticles applied at certain stage of development have the ability to increase the germination rate. ${ }^{1417}$ The development of plants and the reproductive capacities have also been shown to be improved with the use of nanoparticles, which showed that not only nanoparticles improve the growth of the plant but operate on a cellular level to increase the mitotic process. Although there are many beneficial effects to plants that increase viability, there are also some studies that investigated the negative effect of nanoparticles on the plants. ${ }^{1,1820}$

Copper atoms or ions are generally known to be toxic to plants and pose a threat to both agriculture and the environment. Some sources of contamination from copper are a result of industrial, urban, and agricultural wastes in the form of agrochemicals. Copper is readily available in soils, and the bioavailability can be measured by the free $\mathrm{Cu}^{2+}$ ions. ${ }^{14}$ Most of the copper in soil is not free, more than $98 \%$ of $\mathrm{Cu}$ 
is bound to soluble organic matter, thus the concentration of $\mathrm{Cu}$ in the soil is usually extremely low. ${ }^{21}$ Because $\mathrm{Cu}$ has a high affinity for organic matter, it is not easily leached from the soil. As a result, it accumulates in the surface soil. ${ }^{22}$ Although $\mathrm{Cu}$ is one of the essential micronutrients, if there is high exposure, it tends to inhibit the plant growth, specifically in the roots and morphology (external structure). Due to the tendency of $\mathrm{Cu}$ to accumulate in the roots, roots are usually affected more strongly by copper compared to shoots. ${ }^{23}$

Kale was chosen due to its high nutritious value, quick growing cycle, and is grown regularly all over the world. Other studies have utilized kale in combination with nanoparticles to investigate the effects. Some researchers indicate that silver nanoparticles (SNPs) can have both a negative and positive effects on the growth of kale. Because SNPs are present in greywater it is assumed that some are present in soils. Agloro et al investigated the effect of SNPs with the influence of varying capping agents on the uptake by the kale plants. ${ }^{24}$ At the moment there are very few studies utilizing kale in relation to nanoparticles to observe the effect on the plant. ${ }^{24}$ However, the effects of $\mathrm{CuO}$ nanoparticles on the growth of kale have not been investigated, especially utilizing the treatment method presented in this study by treating kale seeds with various concentrations of $\mathrm{CuO}$ nanoparticle solutions. Hence, the aims of this study were to investigate the effects of $\mathrm{CuO}$ nanoparticles to evaluate the potential effects on the growth and development of kale (Brassica oleracea).

\section{Experimental}

Materials: Copper oxide nanoparticles $(<50 \mathrm{~nm}$ in diameter) were commercially obtained from Sigma-Aldrich, USA. Kale seeds were supplied by the Ferry Morse company (whose germination rate is above $75 \%$ ) and commercially purchased from the Valley Garden Center (USA), to ensure the variability of the seeds. Potting mixture (Sunshine 3) was produced by Sun Gro Horticulture and obtained locally from the Kinney Bonded Warehouse, Inc (USA).

Preparation of $\mathrm{CuO}$ nanoparticle solution: Stock solutions of $\mathrm{CuO}$ NPs dispersion in water with concentrations of 30 and $70 \mathrm{ppm}$ were prepared by dispersing them in milli-Q water through ultra-sonication $(400 \mathrm{~W}, 60 \mathrm{kHz})$ for 30 minutes. The same milli-Q water without adding any NPs was used as a control solution. ${ }^{25}$
Seed treatment: The dispersed $\mathrm{CuO}$ NPs were used for kale seed treatment. The kale seeds were first surface sterilized by treating them with $10 \%$ sodium hypochlorite solution for $10 \mathrm{~min}$, and then washed several times with de-ionized water to eliminate hypochlorite from the seed surface. ${ }^{26}$ The seeds were then separated into their various groups viz. 0 (control), $30 \mathrm{ppm}$, and $70 \mathrm{ppm}$, and placed into a $100 \mathrm{~mm} \times 15 \mathrm{~mm}$ sterile petri dish. The seeds were then kept for 24 hours in the aqueous suspension of the dispersed $\mathrm{CuO}$ NPs with their respective concentration 0,30 , and $70 \mathrm{ppm}$. SEM images were taken from the seeds (untreated $v s$ treated) to ensure the coating process was being carried out properly (Fig. 1).

Kale plant growth: The treated kale seeds were directly sown into pots of 4.5 inch in diameter filled with the Sunshine 3 potting mixture quarter inch deep. These pots were randomly positioned in a greenhouse. The plants were grown organically without addition of pesticides, herbicides, or insecticides. The seeds were allowed to germinate and grow in a period of 34 days.

Plant harvesting and parameter measurements: On the $34^{\text {th }}$ day, the plants were harvested manually. After the plants were harvested, they were completely cleared of mud, dirt, and potting soil attached to the roots by repeatedly washing the roots in water. Three plant growth parameters of the obtained kale were observed, collected and studied in this experiment: elongation of shoots, number of leaves, biomass (dry weight and wet weight), and specific leaf area. ${ }^{12}$ More specifically, the elongation of shoots was measured after the plants were washed and prepared for data collection. The root and shoot lengths of the plants were measured from the bottom tip of the root to the base of the stem and then from the base of the stem to the tip of the shoot, respectively. The total length is equal to the sum of the root length and the shoot length. The number of leaves pertaining to each plant was counted manually. To get the leaf area, the average area was calculated by utilizing the $3^{\text {rd }}$ leaf from the shoot apical meristem of each plant and determined using the ImageJ software. Plants were then weighed to obtain the fresh weight. After the fresh weight was obtained, the plants were dried in an oven at $72{ }^{\circ} \mathrm{C}$ for 72 hours and then weighed again to obtain the dry weight. The specific leaf area is represented as the ratio of leaf area divided by the dry mass. This measurement indicates the thickness of the leaves. The formula to calculate the specific leaf area is: Specific leaf area $=$ Leaf area/Dry mass
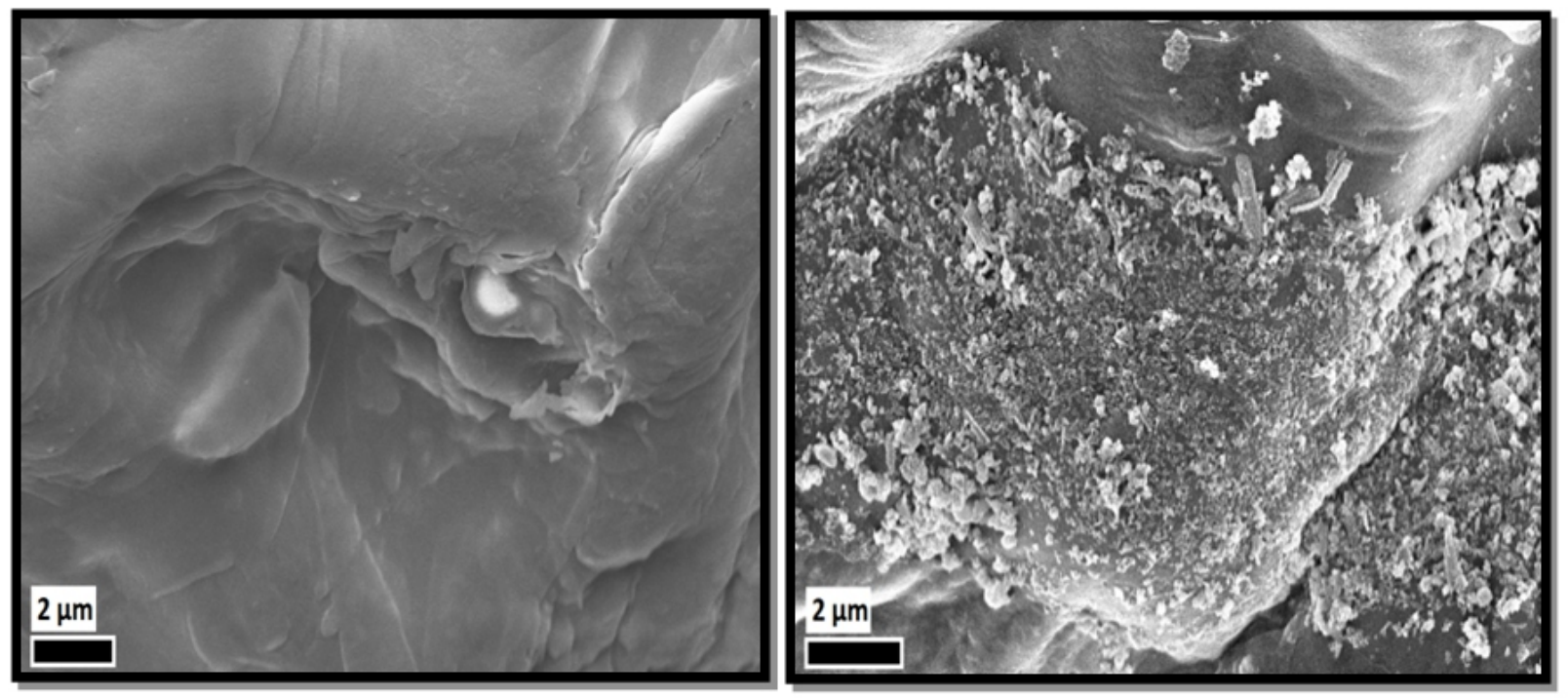

Fig. 1 SEM images of the kale seeds: (a) without and (b) with nano-CuO treatment at the concentration of $70 \mathrm{ppm}$. 


\section{Results and discussion}

Effects on plant lengths

Depending on the used concentration, the $\mathrm{CuO}$ NPs had positive and negative effects on the elongation of the roots and the shoots (Fig. 2, left panel). There was a stable increase in the length of the root, i.e. the kale seeds treated with the highest $\mathrm{CuO}$ concentration gave the longest root. However, the shoot length from both the treated samples was shorter than that of the control sample while the $30 \mathrm{ppm}$ treated plants had the shorted shoot. In the total length measurement, there was variation after the seeds were treated with different concentrations of the $\mathrm{CuO}$ NPs (Fig. 2, right panel). Specifically, there was an initial decrease in the total length of the plant at the concentration of $30 \mathrm{ppm}$, and then as the concentration increased to $70 \mathrm{ppm}$, the total length of the plant increased respective to both the control and $30 \mathrm{ppm}$ treated samples.

\section{Effects on Biomass}

The biomass, especially the dry weight, is one of the most accurate measurements of the growth effect of $\mathrm{CuO}$ NPs on a plant. Due to the different absorption of water by different plants based on their position relative to other plants or external stimuli, the dry weight is one measurement where all the plants are in the same relative condition and state. Regarding the fresh weight (Fig. 3, left panel), the kale plants treated with $30 \mathrm{ppm} \mathrm{CuO}$ NPs were slightly lower than the control plants while the plants treated with high concentration of $70 \mathrm{ppm} \mathrm{CuO}$ NPs showed increased growth and even surpassed the control plants. However, there was a steady increase of both the root and shoot dry weights with the increasing treating concentration of the $\mathrm{CuO}$ NPs (Fig. 3 , right panel). This data indicated that the control plants had higher water content than those treated with the low concentration of $30 \mathrm{ppm}$ $\mathrm{CuO}$ NPs. Especially there was a $66 \%$ increase of the kale shoot grown after the high concentration treatment with $70 \mathrm{ppm} \mathrm{CuO} \mathrm{NPs} \mathrm{relative} \mathrm{to}$ the control plants without the treatment by the $\mathrm{CuO}$ NPs. Thus, $\mathrm{CuO}$ NPs have a positive effect on the growth of kale because of the increased dry weight.
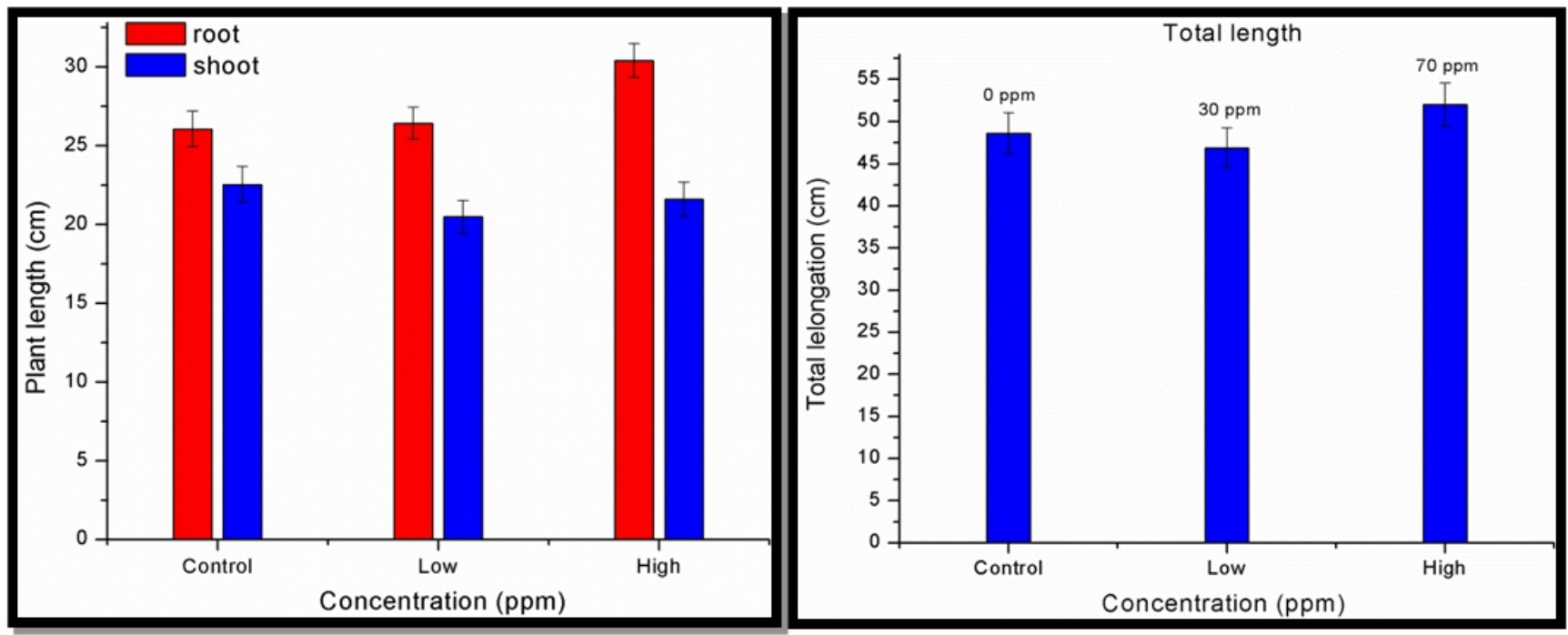

Fig.2 (a) Plant lengths of the root and shoot and (b) total length of the harvested kale after treated the kale seeds with different concentrations of the $\mathrm{CuO}$ NPs.
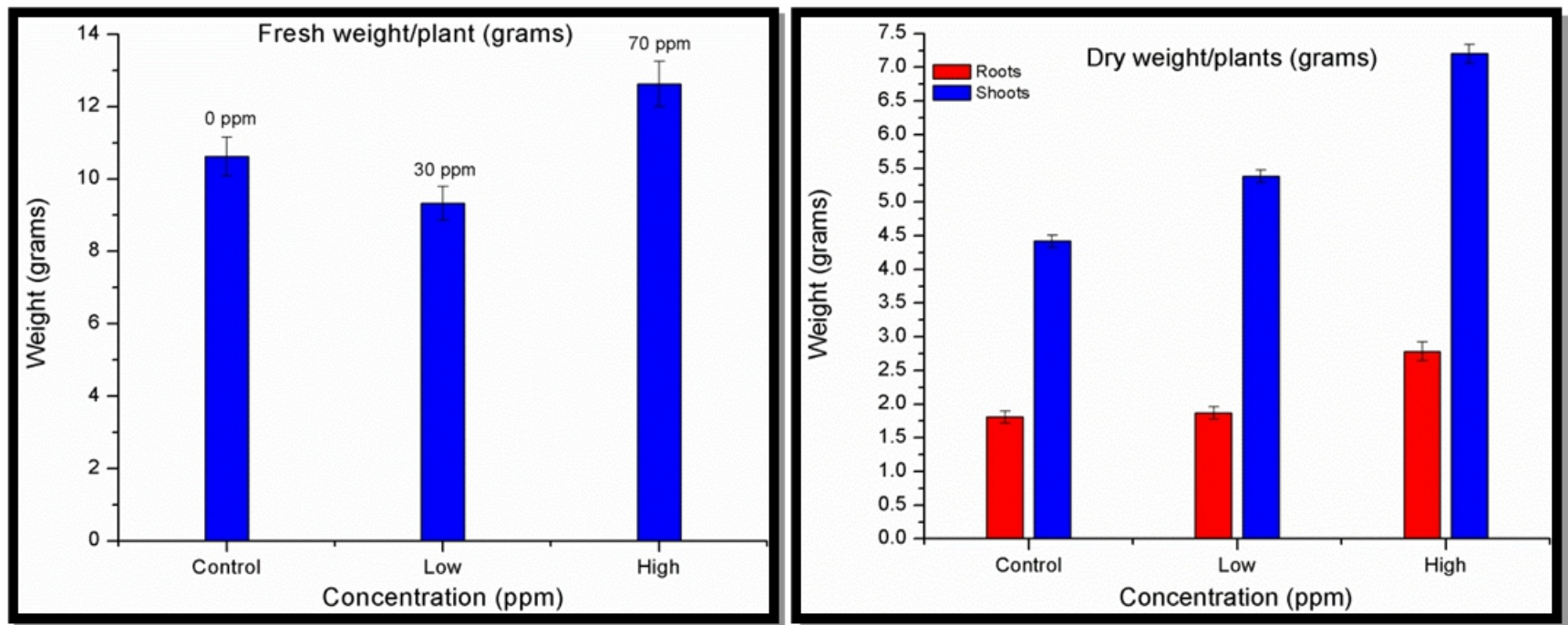

Fig. 3 (a) Fresh weight and (b) dry weight of both roots and shoots of the harvested kale after treated the kale seeds with different concentrations of the $\mathrm{CuO}$ NPs. 


\section{Effects on the leaf number}

The number of leaves per plant was very similar for all the samples treated with different concentrations of $\mathrm{CuO}$ NPs. However, the plants treated with the high concentration of $70 \mathrm{ppm} \mathrm{CuO}$ NPs had the highest number of leaves per plant, and the plants treated with the low concentration of $30 \mathrm{ppm} \mathrm{CuO} \mathrm{NPs} \mathrm{had} \mathrm{the} \mathrm{least} \mathrm{number} \mathrm{of} \mathrm{leaves} \mathrm{per}$ plan (Fig. 4). The number of leaves has a direct correlation to the amount of photosynthesis possible by the plant. The greater the amount of photosynthesis carried out by the plant the more nutrients are made available for the plant growth and development. The greater the number of leaves also indicate an increase in the tissue area to allow for gas exchange per plant. With increased gas exchange, the kale is able to perform photosynthesis at a higher capacity, thus increasing the amount of the conversion of light into sugars metabolized by the plants. Some studies indicate the importance of leaves by studying how light accumulated in leaves while growing in a shaded environment. ${ }^{27}$

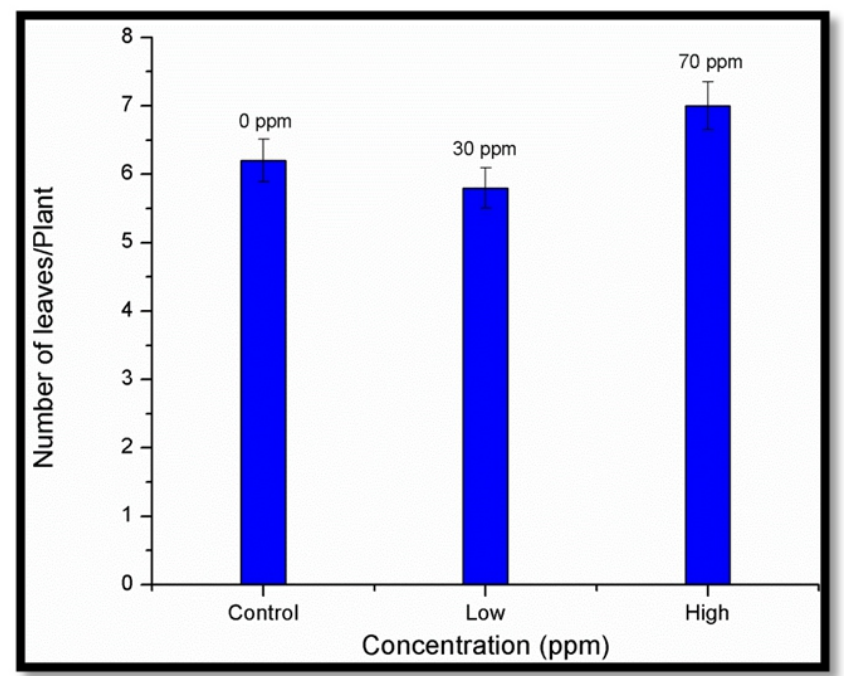

Fig. 4 The number of leaves per the harvested kale plant after treated the kale seeds with different concentrations of the $\mathrm{CuO}$ NPs.

\section{Effects on leaf area}

The leaf area and specific leaf area of the obtained kale were collected (Fig. 5). Kale plants obtained from the seeds treated with the CuO NPs of either the low concentration of $30 \mathrm{ppm}$ or the high concentration of $70 \mathrm{ppm}$ showed positive effect on the leaf area and specific leaf area while the $30 \mathrm{ppm} \mathrm{CuO}$ NPs treated plants had the largest leaf area and specific leaf area compared to the control plants. Thus, the plants from kale seeds treated with the low concentration of $30 \mathrm{ppm} \mathrm{CuO} \mathrm{NPs} \mathrm{were}$ thinner and could not hold as much water as those of the control plants. The thinness of the leaves of the plants grown from the seeds treated with the low concentration of $30 \mathrm{ppm} \mathrm{CuO}$ NPs compared to that of the control plants could explain the difference reported in the fresh weight and the dry weight of these samples. Therefore, the kale plants from the seeds treated with $30 \mathrm{ppm} \mathrm{CuO} \mathrm{NPs} \mathrm{had} \mathrm{a} \mathrm{lower} \mathrm{fresh} \mathrm{weight} \mathrm{while} \mathrm{a}$ higher dry weight than the control plants. This phenomenon signifies the correlation between specific leaf area and leaf thickness. Studies done by Van Kiet et al. also indicated the correlation between dry weight and leaf area. ${ }^{28}$

Specific leaf area signifies leaf thickness and shows significant increase from the kale after treated with the low concentration of 30 ppm $\mathrm{CuO}$ NPs. The thickness of the leaf is important not only to photosynthesis but also to the ability of the plant to retain water. Other published papers indicated that the thicker the leaves of the plant the greater the ability of the plant to grow in water limited conditions. In some cases, the thick leaves showed "dramatically elongated palisade mesophyll cells and, in some cases, increased leaf ploidy". In the study conducted by Coneva, et al, they found that the increased thickness of the leaves increased mesophyll cell size and leaf ploidy levels, suggesting that duplication underpins leaf thickness in tomato. ${ }^{29}$ The thicker the leaf the grater the ability of the plant to perform gas exchange, gas exchange is a major factor in the process of photosynthesis. Some studies have demonstrated the rate of gas exchange based on the amount of leaf tissue. Leaf tissue is vital to the process of photosynthesis, and the thickness of the leaf indicated the mass of the leaf tissue. Therefore, the greater the leaf tissue the greater the volume and rate of photosynthesis, which accounts for an increase in plant development. ${ }^{30}$

Copper oxide is generally known to have a phytotoxic effect on plants. In our current study, $\mathrm{CuO}$ NPs increased the plant growth parameters of leaf area/plant and specific leaf area at the low
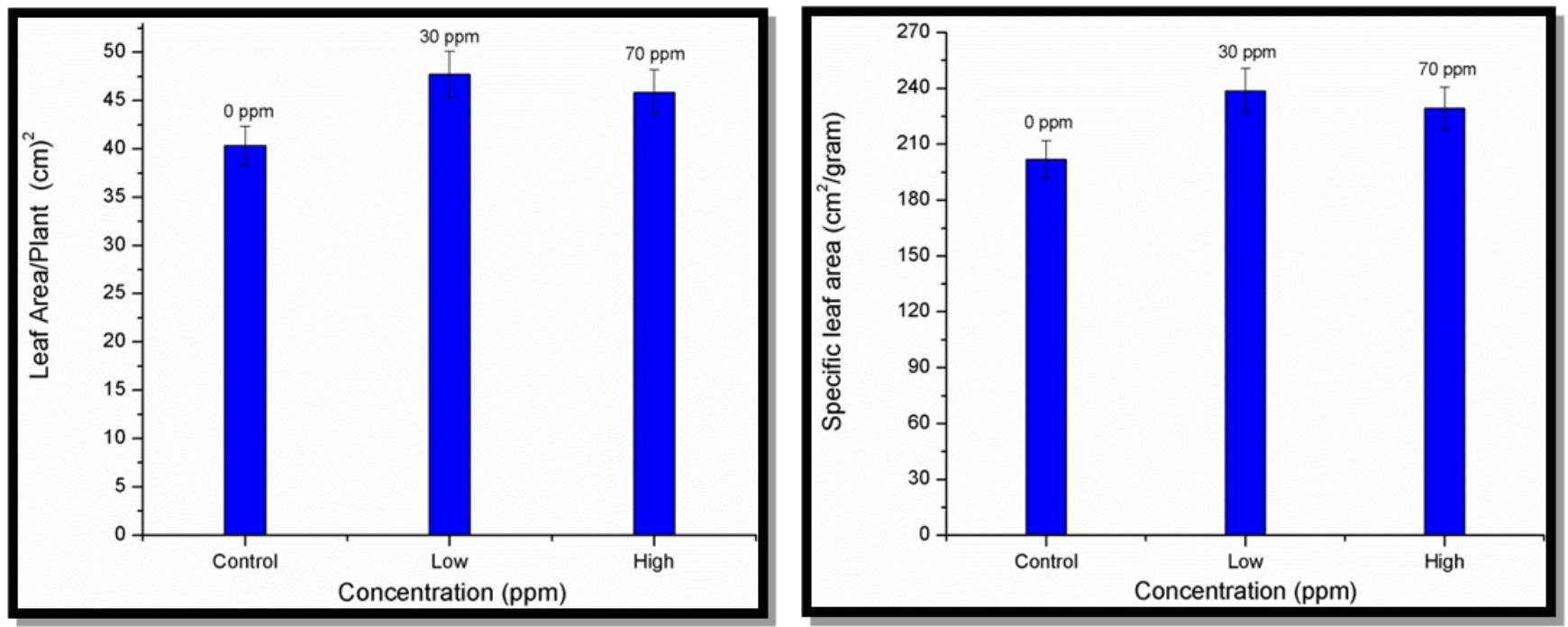

Fig. 5 (a) Leaf area/plant and (b) specific leaf area of the harvested kale plant after treated the kale seeds with different concentrations of the CuO NPs. 
concentration of $30 \mathrm{ppm}$. Nanosized materials tend to behave differently than the same compositions in large particle sizes due to the peculiar characteristics associated with them. Other studies have also found similar results pertaining to the effect of nanosized $\mathrm{CuO}$ in experiments with Spirodela polyrhiza, in which the plant showed sensitivity to concentrations over $0.5 \mathrm{mg} / \mathrm{L} \mathrm{CuO} \mathrm{NPs.}{ }^{26}$ The results from the same study also indicated that a concentration of $\mathrm{CuO}$ NPs higher than 0.5 $\mathrm{mg} / \mathrm{L}$ had a phytotoxic effect on the plant. One research suggested that chitosan-PVA mixed with $\mathrm{Cu}$ NPs had the effect of activating the mechanism of enzymatic defense of tomato plants and increased the content of vitamin $\mathrm{C}$ and lycopene. ${ }^{31-32}$ Another studies found that the use of $\mathrm{Cu}$ NPs had the potential to increase the number of leaves per plant, however, the plant height, fresh weight of stem and leaves, number of fruits and average weight of fruits per plant showed no significant variation from the control. ${ }^{33}$ Some other studies investigated the effect of nanosized $\mathrm{CuO}$ particles at large concentrations on spinach oleracea grown in soil media. ${ }^{18}$ In pertaining to the effect on the shoot and root length, they reported a slight increase at the concentration of 10 $\mathrm{mg} / \mathrm{L}$ and then a decrease once the concentration reached $1000 \mathrm{mg} / \mathrm{L}$. The total weight remained relatively stable until the concentration exceeded $10 \mathrm{mg} / \mathrm{L}$ and then an increase in the total weight at $100 \mathrm{mg} / \mathrm{L}$. In our study reported here, the use of a simple coating method of the seeds before they were planted indicated that the $\mathrm{CuO}$ NPs had a positive effect on the germination and early growth of kale. ${ }^{14}$

\section{Conclusion}

In this study, we coated kale seed with three different concentrations of $\mathrm{CuO}$ nanoparticles, planted them, and then studied their effects on the growth of kale plants. The results showed that the length of the roots and the shoots of the obtained kale were positively affected by the $\mathrm{CuO}$ NPs: while both treated seeds with the $\mathrm{CuO}$ NPs showed increased growth compared with the control sample, larger increase came from the seeds treated with $70 \mathrm{ppm} \mathrm{CuO}$ NPs. Moreover, the dry weight of the kale plants was also impacted by the treatment with $\mathrm{CuO}$ NPs: larger increase was achieved from the seeds treated with $70 \mathrm{ppm} \mathrm{CuO}$ NPs relative to the control. Therefore, this study demonstrated that the application of $\mathrm{CuO}$ NPs to treat the kale seeds at appropriate concentrations could proliferate the growth and development of kale, one of the healthiest vegetables with quick growing cycle. Furthermore, the positive results from this study motivates us to explore the great potentials of nanoscience and nanotechnology on the agriculture and food industries.

\section{Acknowledgment}

The authors thank the support from the USDA National Institute of Food and Agriculture, HSI Collaboration: Integrating Food Science/Engineering and Education Network (IFSEEN, award number: 2015-38422-24059). The Department of Chemistry at the University of Texas Rio Grande Valley is grateful for the generous support provided by a Departmental Grant from the Robert A. Welch Foundation (Grant No. BX-0048).

\section{Conflict of Interest}

The authors declare that they have no conflict of interest. The authors also thank Dr. A. Racelis (UTRGV) for technical support.

\section{References}

1. M. R. Castiglione, L. Giorgetti, C. Geri, R. Cremonini, J. Nanopart. Res., 2011, 13 (6), 2443-2449.

2. H. Mahmoodzadeh, R. Aghili, J. Chem. Health Risks, 2014, 4, 29 - 36.

3. Y. C. Huang, R. Fan, M. A. Grusak, J. D. Sherrier, C. P. Huang, Sci. Total Environ., 2014, 497, 78-90.

4. R. Behra, H. Krug, Nat. Nanotechnol., 2008, 3 (5), 253-254.

5. S. Jin, H. Yao, E. Ellis, M. Zhang, R. R. Naik, L. Dai, Ed. Springer International Publishing: Cham, 2016, 533-542.

6. S. Ali, M. A. Farrukh, M. Khaleeq-ur-Rahman, Korean J. Chem. Eng., 2013, 30 (11), 2100-2107.

7. A. Nasir, Arch. Dermatol., 2008, 144 (2), 253-254

8. A. Khataee, A. Movafeghi, N. Mojaver, F. Vafaei, R. Tarrahi, M. R. Dadpour, Res. Chem. Inte., 2017, 43 (2), 927-941.

9. N. Sadasivam, P.Raju, R. Sivaraj, Int. J. Pharm. Pharmaceut. Sci., 2016, 8 (3), 365-371.

10. L. J. Zhao, J. R. Peralta-Videa, B. Peng, S. Bandyopadhyay, B. Corral-Diaz, P. Osuna-Avila, M. O. Montes, A. A. Keller, J. L. Gardea-Torresdey, J. Environ. Sci-China, 2014, 26 (2), 382-389.

11. P. Mahajan, S. K. Dhoke, A. S. Khanna, J. Nanotechnol., 2011, 7, 696536.

12. Pallavi; C. M. Mehta, R. Srivastava, S. Arora, A. K. Sharma, Biotech, 2016, $6(2), 254$.

13. S. L. Lawre and S. Raskar, Int. J. Curr. Microbiol. Appl. Sci.,2014, 3 (7), 874-881.

14. N. Savithramma, S. Ankanna, G. Bhumi, Nano Vision, 2012, 2, 61-68.

15. A. Mukherjee, J. R. Peralta-Videa, S. Bandyopadhyay, C. M. Rico, L. Zhao, J. L.Gardea-Torresdey, Metallomics, 2014, 6, 132-138.

16. R. Azimi, M. J. Borzelabad, H. Feizi, A. Azimi, , Pol. J. Chem.Technol., 2014, 16 (3), 25-29.

17. A. Parveen, S. Rao, J. Cluster Sci., 2015, 26 (3), 693-701.

18. D. Singh, A. Kumar, B. Environ. Contam. Tox., 2016, 97 (4), 548-553.

19. N. Zuverza-Mena, R. Armendariz, J. L. Gardea-Torresdey, Front. Plant Sci., 2016, 7, 90 .

20. N. Jain, A. Bhargava, V. Pareek, M. S. Akhtar, J. Panwar, Ecotoxicology, 2017, 26 (2), 238-249.

21. S. Sauvé, N. Cook, W. H. Hendershot, M. B. McBride, Environ. Poll., 1996, 94 (2), 153-157.

22. M. B. McBride, B. K. Richards, T. Steenhuis, J. J. Russo, S. Sauvé, Soil Sci., 1997, 162 (7), 487-500.

23. A. R. Sheldon, N. W. Menzies, Plant Soil, 2005, 278, 341-349.

24. A. S. Agloro, L. Arwyn, In 253rd ACS National Meeting \& Exposition, San Francisco, California 2017.

25. M. Zhang, B.Gao, J. Chen, Y. Li, J. Nanopart. Res., 2015, 17 (2), 78

26. B. Kisan, N. K. Shruthi, A. H. Sharanagoud, S. B. Revanappa, R. Ramachandra, A. C. Hosamani, A. N. Bheemann, Pramod, Bioscan, 2015, 10 (3), 1437-1439.

27. J. J. Peguero-Pina, D. Sancho-Knapik, J. Flexas, J. Galmés, Ü. Niinemets, E. Gil-Pelegrín, Tree Phys., 2016, 36 (3), 300-310.

28. H. V. Kiet, A. Nose, Plant Prod. Sci., 2016, 19 (2), 246-256.

29. V. Coneva, M. H. Frank, M. A. L. Balaguer, M. Li, R. Sozzani, D. H. Chitwood, , Plant Phys., 2017, 175 (1), 376-391.

30. P. Morris, J. F.Thain, J. Exp. Bot., 1980, 31 (120), 83-95.

31. H. H. Hernandez, A. Benavides-Mendoza, H. Ortega-Ortiz, A. D. HernandezFuentes, A. Juarez-Maldonado, Emir. J. Food Agr., 2017, 29 (8), 573-580.

32. H. H. Hernández, A. Benavides-Mendoza, H. Ortega-Ortiz, A. D. HernándezFuentes, A. Juárez-Maldonado, Emir. J. Food Agr., 2017, 29 (8), 573-580.

33. H. Hernández-Hernández, S. González-Morales, A. Benavides-Mendoza, H. Ortega-Ortiz, G. Cadenas-Pliego, A. Juárez-Maldonado, Molecules, 2018, 23 (1), 178 .

Publisher's Note Engineered Science Publisher remains neutral with regard to jurisdictional claims in published maps and institutional affiliations. 